\title{
Robust optimization for shape design of arch dams based on grey incidence analysis
}

\author{
L.S. SUN, J. YAN \& H.H. SHU
}

College of Hydraulic, Energy \& Power Engineering, Yangzhou Univ., Yangzhou, Jiangsu, China

\begin{abstract}
KEYWORD: Robust optimization; Arch dam; Grey incidence analysis
\end{abstract}
ABSTRACT: Strain energy of dam body and its sensitivity to the deformation modulus of foundation are taken as objective functions, robust feasibility constraint of stress is proposed with the consideration of uncertain deformation modulus of foundation, and a robust optimization model is established for shape design of arch dams based on strain energy. In the solution process, firstly, utopia solution is obtained by single-objective optimizing of each target. Secondly, based on grey incidence analysis method, a close correlation degree is constructed to measure the degree of closeness of a solution and utopia solution. Finally, robust feasibility optimization model is transformed to a single-objective optimization problem. The calculation of a planned arch dam indicates that compared to the solution of linear weighted method, the optimal design of fuzzy nearness method is closer to utopia solution and is with better dam stress state.

\section{INTRODUCTION}

The research on shape optimization of arch dams began in the late 1960 (Sharpe 1969). In the early research, the optimization is targeted at saving engineering cost (Wasserman 1984, Zhu et al. 1992). With the rapid development of high arch dam construction, people paid more and more attentions on the safety of arch dams, and, in the shape optimization of arch dams, proposed several safety optimization models (Sun et al. 2000) and multi-objective optimization models considering the safety and economical issue (Sun et al. 2006). Existing research on the shape optimization of arch dams is taken in specific design conditions. However, in the construction and operation of arch dams, some conditions, such as, geological conditions, grouting conditions, etc., are different with that adopt in design. That is to say, arch dam design conditions tend to be of some uncertainties. With the thought of robust design, Sun \& Kong (2014) proposed a feasibility robust optimization model for shape design of arch dams with the consideration of uncertainty of foundation deformation modulus. In this paper, the strain energy of dam body and its sensitivity to the deformation modulus of foundation are taken as objective functions; a robust optimization model for shape design of arch dams is established based on strain energy and is transformed to a single objective optimization problem with the introduction of grey incidence; and a planned arch dam is analyzed as an engineering example.

\section{ROBUST OPTIMIZATION MODEL OF ARCH DAMS BASED ON STRAIN ENERGY}

Generally, the mathematical model of shape optimization of arch dams can be expressed as

$$
\begin{cases}\text { find } & \mathbf{X}=\left[\begin{array}{lll}
x_{1} & x_{2} \mathrm{~L} & x_{n}
\end{array}\right]^{\mathrm{T}} \\
\min & F(\mathbf{X}) \\
\text { s.t. } & \sigma_{\mathrm{t} \text { max }}^{\mathrm{eq}} \leq\left[\begin{array}{l}
\sigma_{\mathrm{t} \text { max }}^{\mathrm{eq}}
\end{array}\right] \\
& \sigma_{\mathrm{c} \text { max }}^{\mathrm{eq}} \leq\left[\sigma_{\mathrm{c} \text { max }}^{\mathrm{eq}}\right] \\
& \varphi_{\max } \leq\left[\varphi_{\max }\right] \\
& g_{j}(\mathbf{X}) \leq 0 \quad(j=1,2, \mathrm{~L}, p)\end{cases}
$$

in which, design variables $x_{i}, i=1,2, \ldots, n$, are consist of shape parameters of arch dam; $F(\mathbf{X})$ is objective function; $\sigma_{\mathrm{t} \text { max }}^{\mathrm{eq}}$ and $\left[\sigma_{\mathrm{t} \text { max }}^{\mathrm{eq}}\right]$ are maximum finite element equivalent tensile stress and its al- 
lowable value; $\sigma_{\mathrm{c} \max }^{\mathrm{eq}}$ and $\left[\sigma_{\mathrm{c} \max }^{\mathrm{eq}}\right]$ are maximum finite element equivalent compressive stresses and its allowable value; $\varphi_{\max }$ and $\left[\varphi_{\max }\right]$ are maximum center angle of arch ring and its allowed value; $g_{j}(\mathbf{X}) \leq 0, j=1,2, \ldots, p$, are other geometric constraints, such as boundary constraints of design variables, overhanging constraints, and convex constraints, and so on.

Robust design method was proposed as an optimization method for engineering quality. Its basic idea is to reduce the influence of uncertainty of design factors to design quality, i.e., to improve the robustness of the design. In optimization problem, objective function and constraints are functions of design factors and will be influenced by their uncertainty. Thus, from the perspective of robustness, the robustness of a design contains two aspects, i.e., robustness of objective function and of feasibility of constraints. If feasibility of constraints is robust, constraints still hold when design factors is perturbed. Considering uncertainty of foundation deformation modulus and based on maximum variation analysis, Sun and Kong (2014) proposed robust feasibility constraints such as the formula (2) to replace the stress constraints in optimization problem (1).

$\left\{\begin{array}{l}\max _{\mathbf{E}} \sigma_{\mathrm{t} \text { max }}^{\mathrm{eq}}(\mathbf{X}, \mathbf{E}) \leq\left[\sigma_{\mathrm{t} \text { max }}^{\mathrm{eq}}\right] \\ \max _{\mathbf{E}} \sigma_{\mathrm{c} \text { max }}^{\mathrm{eq}}(\mathbf{X}, \mathbf{E}) \leq\left[\sigma_{\mathrm{c} \text { max }}^{\mathrm{eq}}\right]\end{array}\right.$

where $\mathbf{E}=\left[\mathrm{E}_{1} E_{2} \ldots E_{m}\right]$ are deformation modulus of foundation。

Robustness of the objective function can be described by the absolute value of its derivative with respect to uncertain design factors (Chen 2000). When the objective function is the dam strain energy, $\Pi$, and uncertain design factors are foundation deformation modulus, $E_{i}(i=1,2, \ldots, m)$, the smaller of $\left|\frac{\partial \Pi}{\partial E_{i}}\right|$, the better of the robustness of objective function.

So, considering the uncertainty of foundation deformation modulus, robust optimization model for shape design of arch dams based on dam strain energy can be summarized as follows.

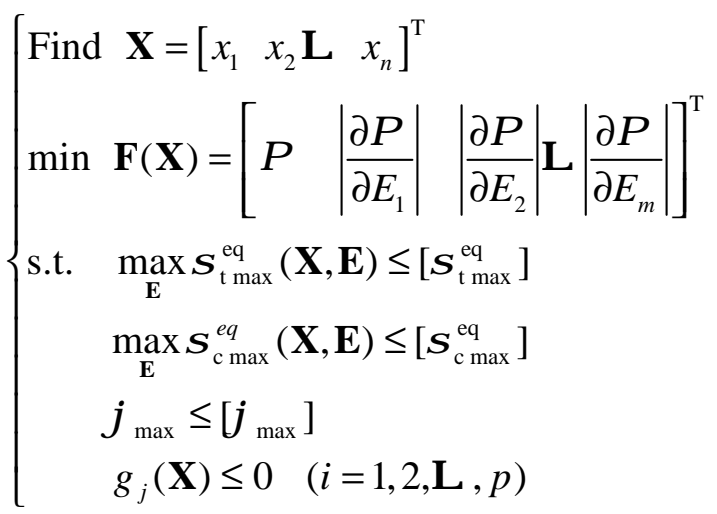

\section{GREY INCIDENCE ANALYSIS METHOD FOR MULTI-OBJECTIVE OPTIMIZATION PROBLEMS}

The grey system theory is first proposed by Deng (1982). It has been widely used in various fields of society, especially in the cross disciplines, and has achieved good economic benefits and social benefits. Grey system refers to the uncertain system of "partial information known, part information is unknown". For such a system, grey system theory uses grey system method and model technology, via the partially known information, to excavate the important data in the system, and to realize the correct description and understanding of the real world. Grey incidence analysis is a very active branch in the grey system theory. Its basic idea is to judge whether the relation between different sequences is closely according to the similarity degree of sequence curves. Grey incidence degree is a quantitative characterization of the degree of correlation between sequences.

Let sequences $\mathbf{X}_{i}=\left[x_{i}(1), x_{i}(2), \ldots, x_{i}(n)\right], \mathbf{X}_{j}=\left[x_{j}(1), x_{j}(2), \ldots, x_{j}(n)\right]$. Liu et al. (2010) proposed a close degree of grey incidence. 
$\rho\left(\mathbf{X}_{i}, \mathbf{X}_{j}\right)=\frac{1}{1+\left|S_{i}-S_{j}\right|}$

where $\left|S_{i}\right|=\left|\frac{1}{2} x_{i}(1)+\sum_{k=2}^{n-1} x_{i}(k)+\frac{1}{2} x_{i}(n)\right| \quad(i, j)$;

$\left|S_{i}-S_{j}\right|=\left|\begin{array}{l}\frac{1}{2}\left[x_{i}(1)-x_{j}(1)\right] \\ +\sum_{k=2}^{n-1}\left[x_{i}(k)-x_{j}(k)\right]+\frac{1}{2}\left[x_{i}(n)-x_{j}(n)\right]\end{array}\right|$.

The close incidence degree can be used to measure the degree of closeness of sequences $\mathbf{X}_{i}$ and $\mathbf{X}_{j}$ in space. The closer of sequences $\mathbf{X}_{i}$ and $\mathbf{X}_{j}$, the larger of $\quad \mathbf{X}_{i}, \mathbf{X}_{j}$ ).

For the multi-objective optimization problem (3), its general form is

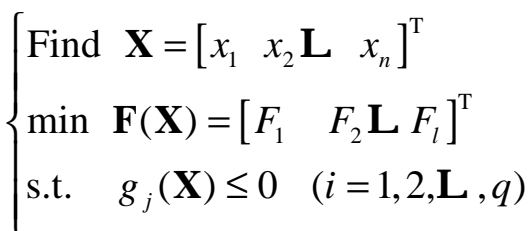

Let the objective vectors at utopia point and any point $\mathbf{X}$ in the design space, i.e., $\mathbf{F}^{*}=\left[F_{1}{ }^{*}, F_{2}{ }^{*}, \ldots\right.$, $\left.F_{l}{ }^{*}\right]$ and $\mathbf{F}=\left[F_{1}, F_{2}, \ldots, F_{l}\right]$, be two sequences, it's obviously that the closer of these two sequences, the better of F. So, multi-objective optimization problem (5) can be transformed to maximize the close incidence degree $\quad\left(\mathbf{F}^{*}, \mathbf{F}\right)$. That is

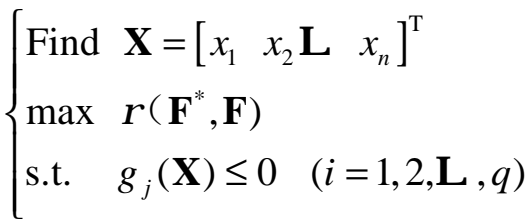

\section{ENGINEERING EXAMPLE}

\section{General information}

A planned elliptical type arch dam is about $289.0 \mathrm{~m}$ height with dam crest elevation of $834.0 \mathrm{~m}$ and dam bottom elevation of $545.0 \mathrm{~m}$. Rocks of dam foundation are classified into 3 types. The deformation parameters of rock mass are shown in table 1, and considering the nature of the three types rock mass, their deformation moduli, $E_{1}, E_{2}$ and $E_{3}$, must meet the relations shown in inequalities (7) and (8).

Table 1. Deformation parameters of rock mass

\begin{tabular}{lllll}
\hline \multirow{2}{*}{$\begin{array}{l}\text { Rock } \\
\text { type }\end{array}$} & \multicolumn{3}{c}{ Modulus of deformation $(\mathrm{GPa})$} & $\begin{array}{l}\text { Pois- } \\
\text { son ra- } \\
\text { tio }\end{array}$ \\
\cline { 2 - 5 } 1 & 13.0 & 19.0 & 16.0 & 0.25 \\
2 & 8.0 & 12.0 & 10.0 & 0.25 \\
3 & 10.0 & 16.0 & 13.0 & 0.22 \\
\hline
\end{tabular}

$1.0 \mathrm{GPa} \leq E_{3}-E_{2} \leq 4.0 \mathrm{GPa}$

$1.0 \mathrm{GPa} \leq E_{1}-E_{3} \leq 4.0 \mathrm{GPa}$

\section{Optimization model}

The mathematical model of robust optimization based on strain energy is written as expression (3), where design variables are shape parameters of crown cantilever and of arch rings at 4 control ele- 
vations. The definition and bounds of design variables are shown in table 2. Constraints in optimization process include bound constraints of design variable, constraints of overhanging degrees on upstream surface $\left(K_{\mathrm{u}} \leq 0.35\right)$ and on downstream surface $\left(K_{\mathrm{d}} \leq 0.30\right)$, constraint of maximal central angle $\left(\max \leq 100^{\circ}\right)$, and constraint of stresses, etc. Additionally, dam volume should be less than $800 \times 10^{4} \mathrm{~m}^{3}$. Finite element method is used as structural analysis method, and arch dam is meshed of 12-layer elements along height and 4-layer elements along thickness. Load combination consists of static pressure of reservoir water at normal water level and of tail water, static pressure of sediment silt, dam body weight, and normal temperature drop. Finite element equivalent stress constraints are that maximal tensile stress and compressive stress are less than $1.5 \mathrm{MPa}$ and $10.0 \mathrm{MPa}$, respectively.

Table 2. Definition and bounds of design variables

\begin{tabular}{|c|c|c|c|c|c|c|c|c|}
\hline \multirow{2}{*}{$\begin{array}{l}\text { Ele- } \\
\text { va- } \\
\text { tion } \\
(\mathrm{m})\end{array}$} & \multicolumn{2}{|c|}{$\begin{array}{c}\text { Parameters of crown } \\
\text { cantilever }\end{array}$} & \multicolumn{3}{|c|}{ Parameters of left arch rings } & \multicolumn{3}{|c|}{ Parameters of right arch rings } \\
\hline & $\begin{array}{l}\text { Coordi- } \\
\text { nates on } \\
\text { upstream } \\
\text { face }(\mathrm{m})\end{array}$ & $\begin{array}{l}\text { Thick- } \\
\text { ness (m) }\end{array}$ & $\begin{array}{l}\text { Thick- } \\
\text { ness of } \\
\text { arch end } \\
(\mathrm{m})\end{array}$ & $\begin{array}{l}\text { Curvature } \\
\text { radius at } \\
\text { arch crown } \\
(\mathrm{m})\end{array}$ & $\begin{array}{l}\text { Semi- } \\
\text { central } \\
\text { angle }\left(^{\circ}\right)\end{array}$ & $\begin{array}{l}\text { Thickness } \\
\text { of arch } \\
\text { end (m) }\end{array}$ & $\begin{array}{l}\text { Curvature } \\
\text { radius at } \\
\text { arch crown } \\
(\mathrm{m})\end{array}$ & $\begin{array}{l}\text { Semi- } \\
\text { central } \\
\text { angle }\left(^{\circ}\right)\end{array}$ \\
\hline $\begin{array}{l}834 . \\
0\end{array}$ & & $\begin{array}{l}x_{4} \\
{[10.0,} \\
20.0]\end{array}$ & $\begin{array}{l}x_{8} \\
{[12.0,} \\
25.0]\end{array}$ & $\begin{array}{l}x_{12} \\
{[300.0,} \\
500.0]\end{array}$ & $\begin{array}{l}x_{16} \\
{[35.0,} \\
50.0]\end{array}$ & $\begin{array}{l}x_{20} \\
{[12.0,} \\
25.0]\end{array}$ & $\begin{array}{l}x_{24} \\
{[200.0,} \\
400.0]\end{array}$ & $\begin{array}{l}x_{28} \\
{[35.0} \\
50.0]\end{array}$ \\
\hline $\begin{array}{l}760 . \\
0\end{array}$ & $\begin{array}{l}x_{1} \\
{[-40.0,} \\
20.0]\end{array}$ & $\begin{array}{l}x_{5} \\
{[35.0} \\
50.0]\end{array}$ & $\begin{array}{l}x_{9} \\
{[35.0} \\
60.0]\end{array}$ & $\begin{array}{l}x_{13} \\
{[200.0,} \\
400.0]\end{array}$ & $\begin{array}{l}x_{17} \\
{[35.0,} \\
50.0]\end{array}$ & $\begin{array}{l}x_{21} \\
{[35.0} \\
60.0]\end{array}$ & $\begin{array}{l}x_{25} \\
{[150.0} \\
350.0]\end{array}$ & $\begin{array}{l}x_{29} \\
{[35.0} \\
50.0]\end{array}$ \\
\hline $\begin{array}{l}640 . \\
0\end{array}$ & $\begin{array}{l}x_{2} \\
{[-60.0,-} \\
40.0]\end{array}$ & $\begin{array}{l}x_{6} \\
{[50.0,} \\
70.0]\end{array}$ & $\begin{array}{l}x_{10} \\
{[55.0} \\
85.0]\end{array}$ & $\begin{array}{l}x_{14} \\
{[150.0,} \\
350.0]\end{array}$ & $\begin{array}{l}x_{18} \\
{[35.0,} \\
50.0]\end{array}$ & $\begin{array}{l}x_{22} \\
{[55.0,} \\
85.0]\end{array}$ & $\begin{array}{l}x_{26} \\
{[150.0} \\
350.0]\end{array}$ & $\begin{array}{l}x_{30} \\
{[35.0} \\
50.0]\end{array}$ \\
\hline $\begin{array}{l}545 . \\
0\end{array}$ & $\begin{array}{l}x_{3} \\
{[-50.0,-} \\
30.0]\end{array}$ & $\begin{array}{l}x_{7} \\
{[60.0,} \\
80.0]\end{array}$ & $\begin{array}{l}x_{11} \\
{[55.0,} \\
85.0]\end{array}$ & $\begin{array}{l}x_{15} \\
{[50.0} \\
250.0]\end{array}$ & $\begin{array}{l}x_{19} \\
{[10.0,} \\
30.0]\end{array}$ & $\begin{array}{l}x_{23} \\
{[55.0,} \\
85.0]\end{array}$ & $\begin{array}{l}x_{27} \\
{[100.0,} \\
300.0]\end{array}$ & $\begin{array}{l}x_{31} \\
{[10.0,} \\
30.0]\end{array}$ \\
\hline
\end{tabular}

\section{Solution method and results}

Considering each objective in formula (3), single objective optimizations are performed and objective functions are compared in table (3).

Table 3. Comparison of objectives in single objective optimal designs

\begin{tabular}{lllll}
\hline Scheme & $\begin{array}{l}\Pi \\
(\mathrm{GJ})\end{array}$ & $\begin{array}{l}\left|\frac{\partial \Pi}{\partial E_{1}}\right| \\
(\mathrm{J} / \mathrm{Pa})\end{array}$ & $\begin{array}{l}\left|\frac{\partial \Pi}{\partial E_{2}}\right| \\
(\mathrm{J} / \mathrm{Pa})\end{array}$ & $\begin{array}{l}\left|\frac{\partial \Pi}{\partial E_{3}}\right| \\
(\mathrm{J} / \mathrm{Pa})\end{array}$ \\
\hline $\min \Pi$ & $\mathbf{3 . 7 6 6 6}$ & 0.3042 & 0.2335 & 0.0912 \\
$\min \left|\frac{\partial \Pi}{\partial E_{1}}\right|$ & 3.9020 & $\mathbf{0 . 2 7 3 9}$ & 0.2135 & 0.0920 \\
$\min \left|\frac{\partial \Pi}{\partial E_{2}}\right|$ & 3.9555 & 0.2810 & $\mathbf{0 . 2 0 3 3}$ & 0.0902 \\
$\min \left|\frac{\partial \Pi}{\partial E_{3}}\right|$ & 3.7695 & 0.2901 & 0.2137 & $\mathbf{0 . 0 8 5 4}$ \\
\hline
\end{tabular}

It's evident that utopia objective vector is $\mathbf{F}^{*}=[3.7666,0.2739,0.2033,0.0854]$. So, it's easy to construct the robust optimization model based on fuzzy nearness according to formulas (3), (4) and (7). The model is solved by accelerated micro-genetic algorithm (Sun \& Zhang 2006). The dam shape parameters of optimal design are shown in table 4. Figure 1 and table 5 show the configuration of crown cantilever and characteristic parameters of dam shape of different design schemes, in 
which, linear weighted method assumes that each objectives have the same weights. Table 6 shows the comparison of key performance indicators of arch dams of the different designs, in which, $\Pi$ and $\left|\frac{\partial \Pi}{\partial E_{i}}\right|$ are dam strain energy and its sensitivity to foundation deformation modulus, respectively; $\sigma_{\mathrm{t} \max }$ and $\sigma_{\mathrm{c} \max }$ are maximum tensile stress and maximum compressive stress, respectively; $\sigma_{\mathrm{t} \max }^{\mathrm{eq}}$ and $\sigma_{\mathrm{cmax}}^{\mathrm{eq}}$ are maximum finite element equivalent tensile stress and maximum finite element equivalent compressive stress, respectively. All the above indicators are computed in the case of design values of foundation deformation modulus being adopted. $\bar{\sigma}_{\mathrm{t} \max }^{\mathrm{eq}}$ and $\bar{\sigma}_{\mathrm{c} \max }^{\mathrm{eq}}$ are maximum finite element equivalent tensile stress and compressive stress, respectively, with the consideration of uncertainty of foundation deformation modulus.

Table 4. Dam shape parameters of optimal design

\begin{tabular}{|c|c|c|c|c|c|c|c|c|}
\hline \multirow[b]{2}{*}{$\begin{array}{l}\text { Elevation } \\
\text { (m) }\end{array}$} & \multirow{2}{*}{\multicolumn{2}{|c|}{$\begin{array}{l}\begin{array}{l}\text { Parameters of crown } \\
\text { cantilever }\end{array} \\
\text { Coordinates } \\
\text { on up- Thickness } \\
\text { stream face }(\mathrm{m}) \\
(\mathrm{m})\end{array}$}} & \multicolumn{3}{|c|}{ Parameters of left arch rings } & \multicolumn{3}{|c|}{ Parameters of right arch rings } \\
\hline & & & $\begin{array}{l}\text { Thickness } \\
\text { of arch } \\
\text { end (m) }\end{array}$ & $\begin{array}{l}\text { Curvature } \\
\text { radius at } \\
\text { arch } \\
\text { crown } \\
\text { (m) }\end{array}$ & $\begin{array}{l}\text { Semi- } \\
\text { central } \\
\text { angle } \\
\left({ }^{\circ}\right)\end{array}$ & $\begin{array}{l}\text { Thickness } \\
\text { of arch } \\
\text { end (m) }\end{array}$ & $\begin{array}{l}\text { Curvature } \\
\text { radius at } \\
\text { arch } \\
\text { crown } \\
\text { (m) }\end{array}$ & $\begin{array}{l}\text { Semi- } \\
\text { central } \\
\text { angle } \\
\left(^{\circ}\right)\end{array}$ \\
\hline 834.0 & 0 & 15.8 & & 449.1611 & 5 & 2 & 317.3993 & 49 \\
\hline 760.0 & -36.9706 & 42.9033 & 50.7816 & 341.4030 & 49.7706 & 51.0123 & 223.5265 & 49.3656 \\
\hline 640.0 & -43.9595 & 64.1484 & 80.1716 & 223.2836 & 45.8353 & 81.6667 & 165.8959 & 49.4186 \\
\hline 545.0 & -30.1387 & 79.5016 & 79.5016 & 140.0466 & 15.8422 & 79.5762 & 139.6042 & 29.9999 \\
\hline
\end{tabular}

Table 5 Comparison of dam shape parameters of different designs

\begin{tabular}{|c|c|c|c|c|c|c|c|}
\hline \multirow{2}{*}{$\begin{array}{l}\text { Design } \\
\text { scheme }\end{array}$} & \multirow{2}{*}{$\begin{array}{l}\text { Dam vo- } \\
\text { lume } \\
\left(10^{4} \mathrm{~m}^{3}\right)\end{array}$} & \multicolumn{2}{|c|}{$\begin{array}{l}\text { Thickness of crown } \\
\text { cantilever }(\mathrm{m})\end{array}$} & \multirow{2}{*}{$\begin{array}{l}\text { Maxi- } \\
\text { mum } \\
\text { thickness } \\
\text { of arch } \\
\text { end (m) }\end{array}$} & \multirow{2}{*}{$\begin{array}{l}\text { Maxi- } \\
\text { mum cen- } \\
\text { ter angle } \\
\left({ }^{\circ}\right)\end{array}$} & \multirow{2}{*}{$\begin{array}{l}\text { Overhang } \\
\text { on up- } \\
\text { stream } \\
\text { surface }\end{array}$} & \multirow{2}{*}{$\begin{array}{l}\text { Overhang } \\
\text { on down- } \\
\text { stream sur- } \\
\text { face }\end{array}$} \\
\hline & & $\begin{array}{l}\text { Top } \\
\text { section }\end{array}$ & $\begin{array}{l}\text { Bottom } \\
\text { section }\end{array}$ & & & & \\
\hline $\begin{array}{l}\text { Linear } \\
\text { weighted } \\
\text { method }\end{array}$ & 830.5143 & 13.7714 & 78.5124 & 83.7521 & 94.3770 & 0.0551 & 0.1247 \\
\hline $\begin{array}{l}\text { Grey inci- } \\
\text { dence me- } \\
\text { thod }\end{array}$ & 823.1618 & 15.8356 & 79.5016 & 81.6667 & 99.1362 & 0.1417 & 0.2514 \\
\hline
\end{tabular}

Table 6 Comparison of key performance indicators of different designs

\begin{tabular}{lcccccccccc}
\hline $\begin{array}{l}\text { Design } \\
\text { scheme }\end{array}$ & $(\mathrm{GJ})$ & $\begin{array}{l}\left|\frac{\partial \Pi}{\partial E_{1}}\right| \\
(\mathrm{J} / \mathrm{Pa})\end{array}$ & $\begin{array}{l}\left|\frac{\partial \Pi}{\partial E_{2}}\right| \\
(\mathrm{J} / \mathrm{Pa})\end{array}$ & $\begin{array}{l}\left|\frac{\partial \Pi}{\partial E_{3}}\right| \\
(\mathrm{J} / \mathrm{Pa})\end{array}$ & $\begin{array}{l}\sigma_{\mathrm{t} \max } \\
(\mathrm{MPa})\end{array}$ & $\begin{array}{l}\sigma_{\mathrm{c} \max } \\
(\mathrm{MPa})\end{array}$ & $\begin{array}{l}\sigma_{\mathrm{t} \max }^{\mathrm{cq}} \\
(\mathrm{MPa})\end{array}$ & $\begin{array}{l}\bar{\sigma}_{\mathrm{tmax}}^{\mathrm{eq}} \\
(\mathrm{MPa})\end{array}$ & $\begin{array}{l}\sigma_{\mathrm{c} \max }^{\mathrm{eq}} \\
(\mathrm{MPa})\end{array}$ & $\begin{array}{l}\bar{\sigma}_{\mathrm{cmax}}^{\mathrm{eq}} \\
(\mathrm{MPa})\end{array}$ \\
\hline $\begin{array}{l}\text { Linear } \\
\text { weighted } \\
\text { method }\end{array}$ & 3.9308 & 0.2852 & 0.2233 & 0.0932 & 3.4256 & 15.4791 & 1.2133 & 1.4975 & 9.2713 & 9.9551 \\
$\begin{array}{l}\text { Grey in- } \\
\text { cidence } \\
\text { method }\end{array}$ & 3.9031 & 0.2686 & 0.2035 & 0.0879 & 3.2692 & 14.7022 & 1.2506 & 1.4959 & 9.2636 & 9.9942 \\
\hline
\end{tabular}

From the point of optimization, all objectives are smaller in grey incidence scheme than that in linear weighted scheme, and it indicates that the solution of grey incidence method is closer to utopia solution. From the point of dam stress state, the dam body maximal tensile stress and maximal 
compressive stress in grey incidence scheme are also less than that in linear weighted scheme, and indicate that the dam shape of grey incidence method is better than that of linear weighted method.

\section{SUMMARY}

In this paper, considering the uncertainty of foundation deformation modulus, taking dam strain energy and its sensitivity to foundation deformation modulus as the objective functions, and considering the robust feasibility of stress constraints, a robust optimization model is proposed for shape design of arch dams based on strain energy. With the use of the close degree of grey incidence between a solution and utopia solution, the robust optimization is transformed to a single objective optimization problem. The calculation of a planned arch dam indicates that compared to the solution of linear weighted method, the optimal design of grey incidence method is closer to utopia solution and is with better dam stress state.

\section{ACKNOWLEDGEMENTS}

This work was financially supported by the National Natural Science Foundation of China (51279174) and A Project Funded by the Priority Academic Program Development of Jiangsu Higher Education Institutions (PAPD).

\section{REFERENCES}

1)Chen, L.Z. 2000. Robust design. Beijing: China Machine Press.

2) Deng, J.L. 1982. Control problem of grey systems. System \& Control Letters, 1 (5): 288-294.

3) Liu, S.F. et al. 2010. On new models of grey incidence analysis base on visual angle of similarity and nearness. Systems Engineering-Theory \& Practice, 30 (5): 881-887

i. Sharpe, R. 1969. The optimum of arch dams. Proceedings of the ICE - Civil Engineering, Suppl: $73-98$

4) Sun, L.S. et al. 2000. Stress Oriented Shape Optimization of Arch Dams. Journal of Hohai University (Natural Science), 28 (1): 57-60.

5) Sun, L.S. et al. 2006. Multi-objective optimization for shape design of parabolic double-curvature arch dams. Dam Engineering. 17 (1): 51-64.

6) Sun, L.S. \& Kong, D.Z. 2014. Robust feasibility optimization for shape design of arch dams with consideration of uncertainty of deformation modulus of foundation rock mass. Advances in Science and Technology of Water Resources, 34 (1): 61-64.

7) Sun, L.S. \& Zhang, W.H. 2006. An Accelerated Micro Genetic Algorithm for Numerical Optimization. Lecture Notes in Computer Science, 4247: 277-283.

8) Wasserman, K. 1984. Three dimensional shape optimization of arch dams with prescribed shape function. Journal of Structural Mechanics, 11(4): 465-489.

9)Zhu, B.F. et al. 1992. Shape optimization of arch dams for static and dynamic loads. Journal of Structural Engineering, 118(11): 2996-3015. 